\title{
Botryosphaeria Dothidea and Neofusicoccum Yunnanense Causing Canker and Die-Back of Sequoiadendron Giganteum in Croatia
}

\author{
Marta Kovač $^{1}\left(\mathbb{D}\right.$, Danko Diminić $^{2}$, Saša Orlović ${ }^{3}$ and Milica Zlatković $^{3, *(D)}$ \\ 1 Croatian Forest Research Institute, Cvjetno Naselje 41, 10450 Jastrebarsko, Croatia; martam@sumins.hr \\ 2 Faculty of Forestry and Wood Technology, University of Zagreb, Svetošimunska Cesta 23, \\ 10000 Zagreb, Croatia; ddiminic@sumfak.hr \\ 3 Institute of Lowland Forestry and Environment (ILFE), University of Novi Sad, Antona Čehova 13d, \\ 21000 Novi Sad, Serbia; sasao@uns.ac.rs \\ * Correspondence: milica.zlatkovic@uns.ac.rs; Tel.: +381-21-540-383
}

Citation: Kovač, M.; Diminić, D.; Orlović, S.; Zlatković, M. Botryosphaeria Dothidea and Neofusicoccum Yunnanense Causing Canker and Die-Back of Sequoiadendron Giganteum in Croatia. Forests 2021, 12, 695. https://doi.org/10.3390/f12060695

Academic Editors: Rostislav Zemek and Katarína Pastirčáková

Received: 15 April 2021

Accepted: 25 May 2021

Published: 28 May 2021

Publisher's Note: MDPI stays neutral with regard to jurisdictional claims in published maps and institutional affiliations.

Copyright: (c) 2021 by the authors. Licensee MDPI, Basel, Switzerland. This article is an open access article distributed under the terms and conditions of the Creative Commons Attribution (CC BY) license (https:/ / creativecommons.org/licenses/by/ $4.0 /)$.

\begin{abstract}
Sequoiadendron giganteum Lindl. [Buchholz] is a long-lived tree species endemic to the Sierra Nevada Mountains in California. Due to its massive size and beauty, S. giganteum is a popular ornamental tree planted in many parts of the world, including Europe. Since 2017, scattered branch die-back has been observed on S. giganteum trees in Zagreb, Croatia. Other symptoms included resinous branch cankers, reddish-brown discoloration of the sapwood and, in severe cases, crown die-back. Branches showing symptoms of die-back and cankers were collected from six S. giganteum trees in Zagreb and the aim of this study was to identify the causal agent of the disease. The constantly isolated fungi were identified using morphology and phylogenetic analyses based on the internal transcribed spacer (ITS) of the ribosomal DNA (rDNA), and partial sequencing of two housekeeping genes, i.e., translation elongation factor 1- $\alpha$ (TEF 1- $\alpha$ ), and $\beta$ tubulin 2 (TUB2). The fungi were identified as Botryosphaeria dothidea (Moug.) Ces. and De Not. and Neofusicoccum yunnanense G.Q. Li \& S.F. Chen. The pathogenicity test was conducted in a plant growth chamber on S. giganteum seedlings and revealed that $N$. yunnanense was more aggressive compared to B. dothidea. N. yunnanense was able to reproduce symptoms of canker and die-back and kill plants seven weeks after inoculation whereas $B$. dothidea produced cankers. To the best of our knowledge, this is the first report of $B$. dothidea and N. yunnanense causing canker and die-back disease of S. giganteum in Croatia. It is also the first record on the identity and pathogenicity of any fungal species associated with S. giganteum in this country. The study expended the known host range of N. yunnanense to include S. giganteum, which is a valuable ornamental tree in Croatian landscapes. Disease management strategies should be developed to mitigate or reduce the impact of the disease.
\end{abstract}

Keywords: Botryosphaeriaceae; phylogeny; giant sequoia; die-back disease; canker disease; urban tree pathogens

\section{Introduction}

Giant sequoia (Sequoiadendron giganteum Lindl. [Buchholz]) is a massive, long-lived, coniferous tree species endemic to the western slopes of the Sierra Nevada Mountains in California, in western North America. Its natural populations are confined to distinct groves with a narrow mid-elevation range of 1400-2150 $\mathrm{m}$ and occupy about 14,600 ha. These groves are in areas with moderate winter temperatures, and relatively abundant summer soil water supply, such as valley bottoms or plateaus receiving snowmelt [1]. S. giganteum is threatened by climate changes due to expected decrease in the amount of soil moisture throughout Sierra Nevada [2]. Moreover, the species is endangered due to competition in the absence of periodic fires, and loss of genetic diversity and has been listed on the IUCN red list of threatened plants $[3,4]$. Outside its natural range, S. giganteum 
is highly regarded as ornamental and it is frequently planted as a large tree for shade or specimen in city parks and private gardens. It is also often planted in the living collections of woody plants such as botanical gardens and arboreta [1].

Sequoiadendron giganteum has been known for its remarkable fire, pest, and pathogen resistance. This is mainly due to its thick resin-free bark and hardwood that is resistant to fungal decay, enabling trees to live for $>3000$ years in the species' native range [1]. However, recently, it was found that severe drought stress in combination with cambial damage from fire and bark beetle attack (Phloeosinus spp.) can increase mortality of S. giganteum [5]. Moreover, in the last decade, a die-back and canker disease of S. giganteum was observed outside of its native range, including urban landscapes of California, France, Germany, Austria, Switzerland, Hungary, Greece, Bulgaria, and Serbia [6-16]. Tests of pathogenicity have shown that the disease has been caused by fungi in the Botryosphaericeae (Ascomycota: Botryosphaeriales), namely Neofusicoccum parvum (Pennycook and Samuels) Crous, Slippers and A.J.L. Phillips, Neofusicoccum nonquaesitum Inderb., Trouillas, Bostock and Michailides, Botryosphaeria dothidea (Moug.) Ces. and De Not. and Dothiorella omnivora Linaldeddu, Deidda and Scanu $[6,14]$.

Fungi in the Botryosphaeriaceae are important tree pathogens causing disease symptoms such as canker, die-back, leaf blight, fruit rot in a wide variety of hosts, including ornamental trees [14-18]. They are also saprophytes, endophytes and latent pathogens behaving pathogenic when plants are exposed to stress conditions such as drought or high temperatures [19]. Botryosphaeriaceae are distributed worldwide and most of these fungi have broad host affinities [14,19]. In the last decade, incidence of diseases caused by Botryosphaeriaceae have been increasing and climate change was speculated to be the main cause for this increase $[13,19]$.

For many years, delimitation of species boundaries within Botryosphaeriaceae has been challenging. This is due to overlapping morphology between species and the existence of cryptic species complexes that cannot be distinguished based on morphology alone or combination of morphology and single gene sequencing, including Neofusicoccum parvum species complex. In recent years, DNA sequence-based phylogenetics and the introduction of a "one fungus-one name" concept have strongly shaped the taxonomy of members of this fungal family. Therefore, the analyses of combined multilocus DNA sequences and genealogical concordance phylogenetic species recognition (GCPSR) principle have become an important tool to infer phylogenetic relationships within Botryosphaeriaceae. The most used loci include the internal transcribed spacer (ITS) of the ribosomal DNA (rDNA), partial translation elongation factor 1- $\alpha$ (TEF 1- $\alpha$ ), partial $\beta$-tubulin 2 gene (TUB2) and DNA-directed RNA polymerase II subunit (rpb2) [20,21].

Since 2017, mature S. giganteum trees (50-140 years old) planted as ornamentals in Zagreb, Croatia have been showing disease symptoms such as scattered branch die-back, resinous branch cankers, reddish-brown internal discoloration of sapwood and in severe cases, crown die-back (Figure 1). About fifty S. giganteum trees had been planted in Zagreb, of which up to $70 \%$ have been showing disease symptoms described above. The symptoms resemble those of a Botryosphaeriaceae-related die-back and canker disease of $S$. giganteum in California and Europe [6-16]. The aim of this study was to determine the causal agent of the disease observed on S. giganteum trees in Zagreb. This was done using morphological characteristics of the asexual morph, phylogenetic analyses of the ITS rDNA, partial TEF $1-\alpha$ and partial TUB2 gene regions, and a pathogenicity test. 

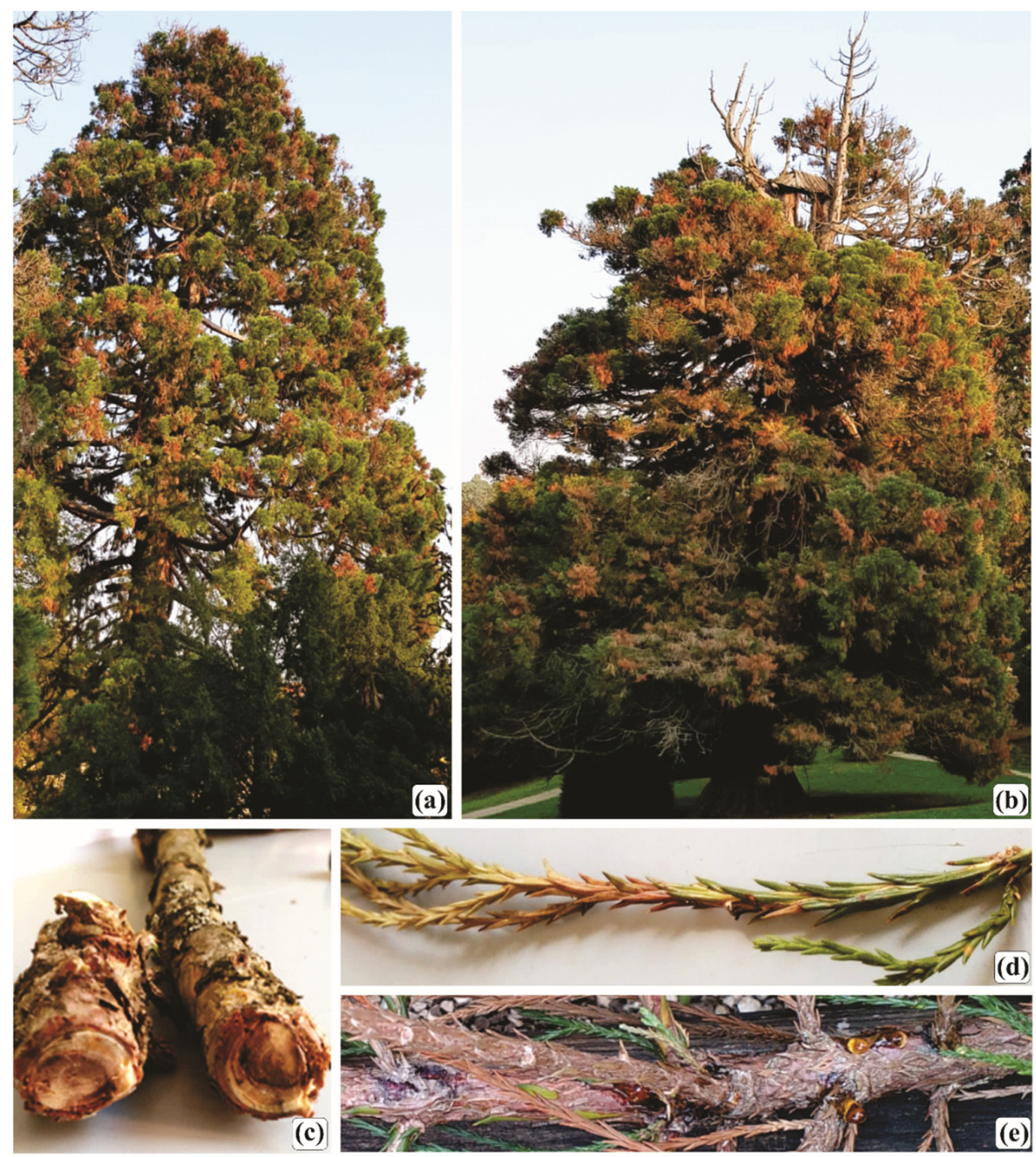

Figure 1. Disease symptoms observed on Sequoiadendron giganteum Lindl. [Buchholz] trees in Zagreb, Croatia. (a). Scattered branch die-back. (b). Top die-back and scattered branch die-back. (c,e). Resinous branch canker (d). Needle die-back.

\section{Materials and Methods}

\subsection{Sample Collection, Fungal Isolation, and Morphological Characterization}

In March 2017, samples were collected from six randomly selected S. giganteum trees experiencing branch and crown die-back in Zagreb, Croatia (Table S1, Figure 1). Five branch parts approximately $20 \mathrm{~cm}$ long with needles showing die-back symptoms and cankered sapwood, which was resin-soaked and discolored at the cross section, were collected from each sampled tree, placed in paper bags, and transferred to the laboratory. Small tissue pieces (3-4 mm diameter) from apparently healthy-to-diseased margins of needles and discolored, resinous sapwood were cut, and surface sterilized as described in Zlatković et al. [13]. Two hundred samples (100 samples of needles and 100 samples of sapwood, five samples per Petri dish) were plated onto $2 \%$ malt extract agar (LabM, Lancaster, UK) plates (MEA) amended with lactic acid (1.6 mL/L, NRK, Belgrade, Serbia, AMEA) to prevent bacterial growth. Petri dishes were sealed using parafilm (Brand, Wertheim, Germany) and incubated at $25^{\circ} \mathrm{C}$ in the dark for two weeks.

The consistently recovered colonies were Botryosphaeriaceae-like (mycelium fast-growing, grey to black, fluffy to appressed) [13]. These colonies were selected, and hyphal tips were 
transferred to fresh MEA using a sterile hypodermic needle. Based on colony morphology, the isolates were then divided into two groups. Depending on the number of isolates available, up to ten isolates from each group were further morphologically characterized. To induce the formation of fruit bodies, isolates were grown on $2 \%$ water agar (WA, LabM, Lancaster, UK) overlaid with triple sterilized Pinus nigra J. F. Arnold needles and kept in the laboratory at room temperature $\left(22-24^{\circ} \mathrm{C}\right)$ under natural day and night cycle for six weeks. The fruiting bodies were sectioned by hand and mounted on microscope slides in distilled water. Morphological characteristics of the fruit bodies and spores were observed using an Olympus SZX10 stereo microscope (Olympus Co., Tokyo, Japan), and an Olympus BX53F light microscope with differential interference contrast. Photographs were taken with an Olympus SC50 digital camera and accompanying software. The lengths and widths of 20 conidia per isolate were measured and the ratio of average length to average width $(1 / w)$ for each species was calculated.

Two representative isolates of each morphologically different group were selected, and further used in this study to identify the fungi. Isolates were stored as mycelium plugs in sterile distilled water at $4{ }^{\circ} \mathrm{C}$ and in $40 \%$ glycerol at $-80{ }^{\circ} \mathrm{C}$. The isolates were deposited in the collection of microorganisms of the Institute of Lowland Forestry and Environment (ILFE).

\subsection{DNA Extraction, PCR Amplification and Phylogenetic Analyses}

Genomic DNA was extracted from one-week-old fungal cultures by gently scraping the mycelium using a sterile scalpel and by following the manufacturer's protocol for the PrepMan Ultra Sample Preparation Reagent (Applied Biosystems, Warrington, UK). The DNA concentrations and quality were measured using a BioSpec-nano spectrophotometer (Shimadzu, Biotech, Japan), at 260 and $280 \mathrm{~nm}$. Afterwards, the DNA was diluted to the concentration of $20 \mathrm{ng} / \mu \mathrm{L}$. The ITS region of the rDNA was amplified using primers ITS1F [22] and ITS 4 [23]. Part of the TEF 1- $\alpha$ gene and part of the TUB2 gene were amplified using primers described in Zlatković et al. [13]. The $25 \mu \mathrm{L}$ PCR reaction mixtures contained $2.5 \mu \mathrm{L}$ of $10 \times$ PCR buffer (100 mM Tris- $\mathrm{HCl}, 500 \mathrm{mM} \mathrm{KCl} \mathrm{(pH} \mathrm{8.3),} \mathrm{Roche} \mathrm{Diagnostics}$ $\mathrm{GmbH}$, Mannheim, Germany), $2-4 \mu \mathrm{L}$ of $25 \mathrm{mM} \mathrm{MgCl}_{2}$ (Roche), $1 \mu \mathrm{L}$ of $100 \mu \mathrm{M}$ of each dNTPs (Thermo Scientific, Vilnius, Lithuania), $0.5 \mu \mathrm{L}$ of $10 \mu \mathrm{M}$ of each primer (Invitrogen, Paisley, UK), $2 \mu \mathrm{L}$ ( $40 \mathrm{ng}$ ) of genomic DNA, $0.5 \mu \mathrm{L}$ (2.5 U) of Taq polymerase (Roche) and 14-16 $\mu \mathrm{L}$ of autoclave-sterilized ultra-pure water treated with a carbon filtration-reverse osmosis-deionizing system (Ecosoft Water Systems GmbH, Nettetal, Germany) and filtered with an Acrodisc Syringe Filter with $0.2 \mu \mathrm{m}$ HT Tuffryn membrane (Pall Corporation, Ann Arbor, MI, USA). Control samples contained sterile ultra-pure water instead of the DNA. The PCR was performed in an Eppendorf Mastercycler epgradient $S$ thermal cycler (Eppendorf AG, Hamburg, Germany) under the following conditions: initial denaturation of 5 min at $95^{\circ} \mathrm{C}$, followed by 35 cycles of $30 \mathrm{~s}$ at $95^{\circ} \mathrm{C}, 30 \mathrm{~s}$ at $55^{\circ} \mathrm{C}$, and $1 \mathrm{~min}$ at $72{ }^{\circ} \mathrm{C}$, and a final extension step of $8 \mathrm{~min}$ at $72^{\circ} \mathrm{C}$. However, the ITS region and TUB2 failed to amplify for some isolates with amplification conditions described above. In these situations, PCRs were performed using a touchdown protocol [24] with annealing temperatures ranging from $61{ }^{\circ} \mathrm{C}$ to $55^{\circ} \mathrm{C}$ or $65^{\circ} \mathrm{C}$ to $55^{\circ} \mathrm{C}$ (Table S2).

The amplified products were analysed by electrophoresis on $2 \%(w / v)$ agarose gels (Serva Electrophoresis GmbH, Heidelberg, Germany) in $0.5 \times$ TBE buffer, stained with Roti-GelStain (Carl Roth GmbH + Co. KG, Karlsruhe, Germany) and visualized with UV illumination. The DNA molecular weight marker (O'GeneRuler 100 bp DNA ladder, Thermo Scientific, Vilnius, Lithuania) was used to estimate the size of the products. The PCR products were purified with the QIAquick PCR Purification Kit (Qiagen, Hilden, Germany) following the manufacturer's instructions, and sequenced by Macrogen Europe (Amsterdam, The Netherlands). Sequencing proceeded in both directions, using the same primers as used for the PCR reactions.

Sequences were examined, edited, assembled, and multiple sequence alignments were done using BioEdit v. 7.2.5, MEGA $X$ and MAFFT v. 7 as described in Zlatković 
et al. [25]. Sequence data of the three loci (ITS, tef 1- $\alpha$, TUB2) were analysed individually and in combination, to assure that the evolutionary lineage is consistent in most of the analysed phylogenies [26]. The phylogenetic analyses of the individual genes were done using Maximum Likelihood (ML) and Bayesian Interference (BI) analyses, whereas the analyses of the combined dataset (ITS + tef 1- $\alpha+$ TUB2) were performed using ML, Maximum parsimony (MP) and BI. The ML and MP analyses were conducted using PhyML v. 3.0 (http:/ / www.atgc-montpellier.fr/phyml/, accessed on 13 April 2021) and PAUP v. 40b10 following the methods described by Zlatković et al. [25] and Zlatković et al. [13], respectively. The partition homogeneity test (PHT) was done in PAUP v. 40B10 [13]. The BI analyses were done in MrBayes v. 3.0b4 as described previously [27] but using the best nucleotide substitution model previously generated by the smart model selection option based on the Akaike information criterion during the ML analyses [28]. Pseudofusicoccum stromaticum Mohali, Slippers and M.J. Wingfield (CBS 117448, CBS 117449) served as outgroup. The DNA sequences generated in this study were deposited in the GenBank database (Table 1).

Table 1. Sequences used in the phylogenetic analyses.

\begin{tabular}{|c|c|c|c|c|c|c|c|}
\hline \multirow[t]{2}{*}{ Isolate No. ${ }^{1,2}$} & \multirow[t]{2}{*}{ Identity } & \multirow[t]{2}{*}{ Host } & \multirow[t]{2}{*}{ Location } & \multirow[t]{2}{*}{ Collector } & \multicolumn{3}{|c|}{ GenBank Accession No. ${ }^{3,4}$} \\
\hline & & & & & ITS & tef $1-\alpha$ & TUB2 \\
\hline ILFE 2 & $\begin{array}{l}\text { Botryosphaeria } \\
\text { dothidea }\end{array}$ & $\begin{array}{l}\text { Sequoiadendron } \\
\text { giganteum }\end{array}$ & $\begin{array}{l}\text { Zagreb, } \\
\text { Croatia }\end{array}$ & M. Kovač & MW033525 & MW051688 & MW051690 \\
\hline ILFE 3 & B. dothidea & S. giganteum & $\begin{array}{l}\text { Zagreb, } \\
\text { Croatia }\end{array}$ & M. Kovač & MW033526 & MW051689 & MW051691 \\
\hline CMW 39308 & B. dothidea & S. giganteum & $\begin{array}{l}\text { Valjevo, } \\
\text { Serbia }\end{array}$ & N. Keča & KF575008 & KF575040 & KF575104 \\
\hline CBS 110302 & B. dothidea & Vitis vinifera & Portugal & A.J.L. Phillips & AY259092 & AY573218 & EU673106 \\
\hline CMW 8000 & B. dothidea & Prunus sp. & $\begin{array}{l}\text { Crocifisso, } \\
\text { Switzerland }\end{array}$ & B. Slippers & AY236949 & AY236898 & AY236927 \\
\hline CERC 2947 & $\begin{array}{l}\text { B. } \\
\text { qingyuanensis }\end{array}$ & $\begin{array}{l}\text { Eucalyptus } \\
\text { hybrid }\end{array}$ & China & $\begin{array}{l}\text { S.F.Chen \& } \\
\text { G.Q.Li }\end{array}$ & KX278001 & KX278106 & KX278210 \\
\hline CERC 2946 & $\begin{array}{l}\text { B. } \\
\text { qingyuanensis }\end{array}$ & $\begin{array}{l}\text { Eucalyptus } \\
\text { hybrid }\end{array}$ & China & $\begin{array}{l}\text { S.F.Chen \& } \\
\text { G.Q.Li }\end{array}$ & KX278000 & KX278105 & KX278209 \\
\hline CBS 135219 & B. kuwatsukai & $\begin{array}{l}\text { Malus } \\
\text { domestica }\end{array}$ & China & C.S. Wang & KJ433388 & KJ433410 & - \\
\hline LSP 5 & B. kuwatsukai & Pyrus sp. & China & C.S. Wang & KJ433395 & KJ433417 & - \\
\hline CBS 127194 & B. fabicerciana & Eucalyptus sp. & China & M.J. Wingfield & HQ332198 & HQ332214 & KF779069 \\
\hline CBS 127193 & B. fabicerciana & Eucalyptus sp. & China & M.J. Wingfield & HQ332197 & HQ332213 & KF779068 \\
\hline ATCC 22927 & B. corticis & Vaccinium sp. & $\begin{array}{l}\text { North } \\
\text { Carolina, } \\
\text { USA }\end{array}$ & $\begin{array}{l}\text { R.D. } \\
\text { Millholland }\end{array}$ & DQ299247 & EU673291 & EU673108 \\
\hline CBS 119047 & B. corticis & $\begin{array}{l}\text { V. } \\
\text { corymbosum }\end{array}$ & USA & P.V. Oudemans & DQ299245 & EU017539 & EU673107 \\
\hline CBS 124702 & B. scharifii & $\begin{array}{l}\text { Magnifera } \\
\text { indica }\end{array}$ & Iran & $\begin{array}{l}\text { J. Abdol- } \\
\text { lahzadeh \& A. } \\
\text { Javadi }\end{array}$ & JQ772019 & JQ772056 & - \\
\hline CBS 124703 & B. scharifii & M. indica & Iran & $\begin{array}{l}\text { J. Abdol- } \\
\text { lahzadeh }\end{array}$ & JQ772020 & JQ772057 & - \\
\hline $\begin{array}{l}\text { CGMCC } \\
3.18004\end{array}$ & B. ramosa & Acacia sp. & $\begin{array}{l}\text { Hainan, } \\
\text { China }\end{array}$ & $\begin{array}{l}\text { Z.P. Dou \& W. } \\
\text { He }\end{array}$ & KX197073 & KX197093 & KX197100 \\
\hline CBS 122069 & B. ramosa & $\begin{array}{l}\text { E. } \\
\text { camaldulensis }\end{array}$ & Australia & T.I. Burgess & EU144055 & EU144070 & KF766132 \\
\hline CBS 141505 & B. agaves & Agave sp. & France & P.W. Crous & KX306750 & MT592030 & MT592463 \\
\hline CBS 133992 & B. agaves & Agave sp. & Thailand & R. Phookamsak & JX646791 & JX646856 & JX646841 \\
\hline
\end{tabular}


Table 1. Cont.

\begin{tabular}{|c|c|c|c|c|c|c|c|}
\hline \multirow[t]{2}{*}{ Isolate No. ${ }^{1,2}$} & \multirow[t]{2}{*}{ Identity } & \multirow[t]{2}{*}{ Host } & \multirow[t]{2}{*}{ Location } & \multirow[t]{2}{*}{ Collector } & \multicolumn{3}{|c|}{ GenBank Accession No. ${ }^{3,4}$} \\
\hline & & & & & ITS & tef $1-\alpha$ & TUB2 \\
\hline CBS 116131 & $\begin{array}{l}\text { Neofusicoccum } \\
\text { arbuti }\end{array}$ & $\begin{array}{l}\text { Arbutus } \\
\text { menziesii }\end{array}$ & USA & M. Elliott & AY819720 & KF531792 & KF531793 \\
\hline CBS 117090 & N. arbuti & A. menziesii & USA & M. Elliott & AY819724 & KF531791 & KF531794 \\
\hline CBS 126655 & $\begin{array}{l}\text { N. } \\
\text { nonquaesitum }\end{array}$ & $\begin{array}{l}\text { Umbellularia } \\
\text { californica }\end{array}$ & USA & F.P. Trouillas & GU251163 & GU251295 & GU251823 \\
\hline CBS 133501 & $\begin{array}{l}\text { N. } \\
\text { nonquaesitum }\end{array}$ & $\begin{array}{l}\text { Persea } \\
\text { americana }\end{array}$ & USA & A. Eskalen & MT587498 & MT592213 & MT592705 \\
\hline $\begin{array}{l}\text { CGMCC } \\
3.18313\end{array}$ & N. illicii & Illicium verum & $\begin{array}{l}\text { Guangxi, } \\
\text { China }\end{array}$ & L. Wang & KY350152 & KY817758 & KY350158 \\
\hline $\begin{array}{l}\text { CGMCC } \\
3.18311\end{array}$ & N. illicii & I. verum & $\begin{array}{l}\text { Guangxi, } \\
\text { China }\end{array}$ & L. Wang & KY350150 & KY817756 & KY350156 \\
\hline CBS 123634 & N. cordaticola & $\begin{array}{l}\text { Syzygium } \\
\text { cordatum }\end{array}$ & South Africa & D. Pavlić & EU821898 & EU821868 & EU821838 \\
\hline CBS 123635 & N. cordaticola & S. cordatum & South Africa & D. Pavlić & EU821903 & EU821873 & EU821843 \\
\hline CMM 1285 & N. brasilliense & $\begin{array}{l}\text { Mangifera } \\
\text { indica }\end{array}$ & Brazil & M.W. Marques & JX513628 & JX513608 & KC794030 \\
\hline CMM 1338 & $\begin{array}{l}\text { N. brasilliense } \\
\text { N. }\end{array}$ & M. indica & Brazil & M.W. Marques & JX513630 & JX513610 & KC794031 \\
\hline CBS 123639 & $\begin{array}{l}\text { kwambonam- } \\
\text { biense }\end{array}$ & S. cordatum & South Africa & D. Pavlić & EU821900 & EU821870 & EU821840 \\
\hline CBS 123641 & $\begin{array}{l}\text { kwambonam- } \\
\text { biense }\end{array}$ & S. cordatum & South Africa & D. Pavlić & EU821919 & EU821889 & EU821859 \\
\hline CBS 121.26 & N. ribis & Ribes rubrum & $\begin{array}{l}\text { New York, } \\
\text { USA }\end{array}$ & N.E. Stevens & AF241177 & AY236879 & AY236908 \\
\hline CBS 115475 & N. ribis & Ribes sp. & USA & $\begin{array}{l}\text { B. Slippers \& G. } \\
\text { Hudler }\end{array}$ & AY236935 & AY236877 & AY236906 \\
\hline CERC 3416 & $\begin{array}{l}\text { N. } \\
\text { sinoeucalypti }\end{array}$ & $\begin{array}{l}\text { Eucalyptus } \\
\text { hybrid }\end{array}$ & $\begin{array}{l}\text { Guangxi, } \\
\text { China }\end{array}$ & $\begin{array}{l}\text { S.F. Chen \& } \\
\text { G.Q. Li }\end{array}$ & KX278064 & KX278169 & KX278273 \\
\hline CERC 2005 & $\begin{array}{l}\mathrm{N} \text {. } \\
\text { sinoeucalypti }\end{array}$ & $\begin{array}{l}\text { E. urophylla } \times \\
\text { E. grandis }\end{array}$ & $\begin{array}{l}\text { Guangdong, } \\
\text { China }\end{array}$ & $\begin{array}{l}\text { S.F. Chen \& } \\
\text { G.Q. Li }\end{array}$ & KX278061 & KX278166 & KX278270 \\
\hline CBS 128008 & N. occulatum & $\begin{array}{l}\text { E. grandis } \\
\text { hybrid }\end{array}$ & Australia & T.I. Burgess & EU301030 & EU339509 & EU339472 \\
\hline MUCC 286 & N. occulatum & E. pellita & Australia & T.I. Burgess & EU736947 & EU339511 & EU339474 \\
\hline CSF 5721 & N. dianense & E. globulus & $\begin{array}{l}\text { YunNan, } \\
\text { China }\end{array}$ & $\begin{array}{l}\text { S.F. Chen \& } \\
\text { G.Q. Li }\end{array}$ & MT028608 & MT028774 & MT028940 \\
\hline CSF 6075 & N. dianense & $\begin{array}{l}\text { E. urophylla } \times \\
\text { E. grandis }\end{array}$ & $\begin{array}{l}\text { YunNan, } \\
\text { China }\end{array}$ & $\begin{array}{l}\text { S.F. Chen \& } \\
\text { G.Q. Li }\end{array}$ & MT028605 & MT028771 & MT028937 \\
\hline CSF 6142 & N. yunnanense & E. globulus & $\begin{array}{l}\text { YunNan, } \\
\text { China }\end{array}$ & $\begin{array}{l}\text { S.F. Chen \& } \\
\text { G.Q. Li }\end{array}$ & MT028667 & MT028833 & MT028999 \\
\hline CSF 6034 & N. yunnanense & $\begin{array}{l}\text { E. urophylla } \times \\
\text { E. grandis }\end{array}$ & $\begin{array}{l}\text { YunNan, } \\
\text { China }\end{array}$ & $\begin{array}{l}\text { S.F. Chen \& } \\
\text { G.Q. Li }\end{array}$ & MT028672 & MT028838 & MT029004 \\
\hline ILFE 4 & N. yunnanense & S. giganteum & $\begin{array}{l}\text { Zagreb, } \\
\text { Croatia }\end{array}$ & M. Kovač & MW085805 & MW071142 & MW071144 \\
\hline ILFE 5 & N. yunnanense & S. giganteum & $\begin{array}{l}\text { Zagreb, } \\
\text { Croatia }\end{array}$ & M. Kovač & MW085806 & MW071143 & MW071145 \\
\hline CMW 39327 * & N. yunnanense & S. giganteum & $\begin{array}{l}\text { Belgrade, } \\
\text { Serbia }\end{array}$ & M. Zlatković & KF729050 & KF729380 & KF729340 \\
\hline $\begin{array}{l}\text { CMW } 9080 \\
\text { CMW } 9081\end{array}$ & $\begin{array}{l}\text { N. paroum } \\
\text { N. parvum }\end{array}$ & $\begin{array}{l}\text { Populus nigra } \\
\text { P. nigra }\end{array}$ & $\begin{array}{l}\text { New Zealand } \\
\text { New Zealand }\end{array}$ & $\begin{array}{l}\text { G. J. Samuels } \\
\text { G.J. Samuels }\end{array}$ & $\begin{array}{l}\text { AY236943 } \\
\text { AY236943 }\end{array}$ & $\begin{array}{l}\text { AY236888 } \\
\text { AY236888 }\end{array}$ & $\begin{array}{l}\text { AY236917 } \\
\text { AY236917 }\end{array}$ \\
\hline $\begin{array}{l}\text { CGMCC } \\
3.18748\end{array}$ & $\begin{array}{l}\text { N. } \\
\text { hongkongense }\end{array}$ & $\begin{array}{l}\text { Araucaria } \\
\text { cunninghamii }\end{array}$ & $\begin{array}{l}\text { Hong Kong, } \\
\text { China }\end{array}$ & S.F. Chen & KX278051 & KX278156 & KX278260 \\
\hline $\begin{array}{l}\text { CGMCC } \\
3.18747\end{array}$ & $\begin{array}{l}\text { N. } \\
\text { hongkongense }\end{array}$ & A. cunninghamii & $\begin{array}{l}\text { Hong Kong, } \\
\text { China }\end{array}$ & S.F. Chen & KX278050 & KX278155 & KX278259 \\
\hline CBS 117448 & $\begin{array}{l}\text { Pseudofusicoccum } \\
\text { stromaticum }\end{array}$ & $\begin{array}{l}\text { Eucalyptus } \\
\text { hybrid }\end{array}$ & Venezuela & S. Mohali & AY693974 & AY693975 & EU673094 \\
\hline CBS 117449 & P. stromaticum & $\begin{array}{l}\text { Eucalyptus } \\
\text { hybrid }\end{array}$ & Venezuela & S. Mohali & DQ436935 & DQ436936 & EU673093 \\
\hline
\end{tabular}

\footnotetext{
${ }^{1}$ Ex-type or ex-epitype strains are shown in italic. ${ }^{2}$ Strains sequenced in this study are shown in bold. ${ }^{3}$ ITS: Internal Transcribed Spacer; tef 1- $\alpha$ : partial translation elongation factor 1-alpha gene; TUB2: partial beta-tubulin 2 gene. ${ }^{4}$ Dashes indicate that the corresponding sequence was not available in GenBank. * Previously identified as N. parvum in [14]. ATCC: American Type Culture Collection, Virginia, USA; CBS: Culture Collection of the Westerdijk Fungal Biodiversity Institute, Utrecht, the Netherlands; CERC: Culture Collection of the China Eucalypt Research Centre, Chinese Academy of Forestry, ZhanJiang, GuangDong Province, China; CGMCC: China General Microbiological Culture Collection, Beijing, China; CMM: Culture Collection of Phytopathogenic Fungi “Prof. Maria Menezes", University of Pernambuco, Recife, Brazil; CMW: Culture Collection of the Forestry and Agricultural Biotechnology Institute (FABI), University of Pretoria, South Africa; ILFE: Collection of Microorganisms of the Institute of Lowland Forestry and Environment, University of Novi Sad, Serbia; MUCC: Culture Collection of Murdoch University, Perth, Australia.
} 


\subsection{Path ogenicity Test and Statistical Analysis}

One isolate of each species identified, i.e., ILFE 2 (B. dothidea) and ILFE 4 (N. yunnanense G.Q. Li \& S.F. Chen) was randomly selected for pathogenicity test. The test was performed on potted three-years-old S. giganteum seedlings purchased from an ornamental plant nursery Iris MBM d.o.o. After purchase, the seedlings ( $40-45 \mathrm{~cm}$ high with a 0.7 to $0.8 \mathrm{~cm}$ trunk diameter at the soil line) were kept in a growth chamber $\left(23{ }^{\circ} \mathrm{C}, 70 \%\right.$ humidity, $12 / 12 \mathrm{~h}$ day/night cycle) for two weeks and watered every other day to attain field water capacity. Ten plants per isolate were used to inoculate a total of 20 plants and ten plants were mock inoculated using uncolonized MEA plugs to serve as controls. The bark was surface sterilized using $70 \%$ ethanol $(v / v)$ and a $3 \mathrm{~mm}$ wound was made $3-4 \mathrm{~cm}$ above the soil line using a sterilized cork borer. Mycelial plugs ( $3 \mathrm{~mm}$ diam.) were taken from the margins of one week old colonies and placed in the wounds, with the mycelium facing the vascular tissue. Inoculation points were covered with sterile moist cotton wool and wrapped with parafilm to prevent desiccation and contamination. The inoculated plants were arranged in a completely randomized design and maintained in a growth chamber under the conditions described above. The test lasted for seven weeks, i.e., until the first inoculated plant was killed. When the experiment was terminated, the outer bark was removed and the lengths of cankers upwards and downwards from the point of inoculation were measured. Pieces of necrotic tissue from the edge of each canker were surface disinfected as described in Zlatković et al. [13] and plated onto AMEA to isolate the inoculated fungi and complete Koch's postulates. The identity of the recovered fungi was verified using morphology of fungal colonies and spores as described previously.

Statistical analyses were done with Statistica 12.0 (StatSoft Inc., Tulsa, OK, USA). Normality and homogeneity of variances were checked using One sample Kolmogorov-Smirnov test and Leven's test. The differences in canker lengths between the two fungal isolates were assessed using nonparametric Mann-Whitney $\mathrm{U}$ test at $\alpha=0.05$.

\section{Results}

\subsection{Fungal Isolation, and Morphological Characterization}

In total, isolations yielded 91 Botryosphaeriaceae-like isolates (63.6\% were isolated from cankered sapwood, and $36.4 \%$ from needles experiencing die-back). The isolates were divided into two groups based on colony morphology, i.e., group 1: colonies grey and fluffy ( $91.2 \%$ of all isolates), group 2 : colonies black, with appressed mycelial mat $(8.8 \%$, Figure 2).

Isolates produced mature fruit bodies (pycnidia) after seven weeks of growing on WA overlaid with pine needles. Pycnidia of the group 1 were black, sometimes with sparse grey mycelial hairs, globose, up to $500 \mu \mathrm{m}$ wide, solitary, semi-immersed to superficial, unilocular with a central ostiole. Conidiogenous cells were with annellations. Conidia were hyaline, narrowly fusiform, or fusiform, smooth with granular content, aseptate, measuring $21-31.9 \times 7.1-8.7$ (av. $25.3 \times 7.8,1 / \mathrm{w} 3.2) \mu \mathrm{m}$. Pycnidia of the group 2 were black, covered with long, light grey mycelial hairs, globose, up to $700 \mu \mathrm{m}$ wide, solitary, semi-immersed to superficial, unilocular with a central ostiole. Conidiogenous cells were proliferating percurrently with indistinct annellations. Conidia were hyaline, fusiform to ellipsoidal, smooth with granular content, aseptate, measuring $15.4-19.4 \times 6-8.1$ (av. $17.8 \times 6.7,1 / \mathrm{w} 2.7) \mu \mathrm{m}$ (Figure 2). Based on morphological characteristics the isolates were preliminary identified as Botryosphaeria spp. (group 1) and Neofusicoccum spp. (group 2) in the Botryosphaeriaceae (Ascomycota). 

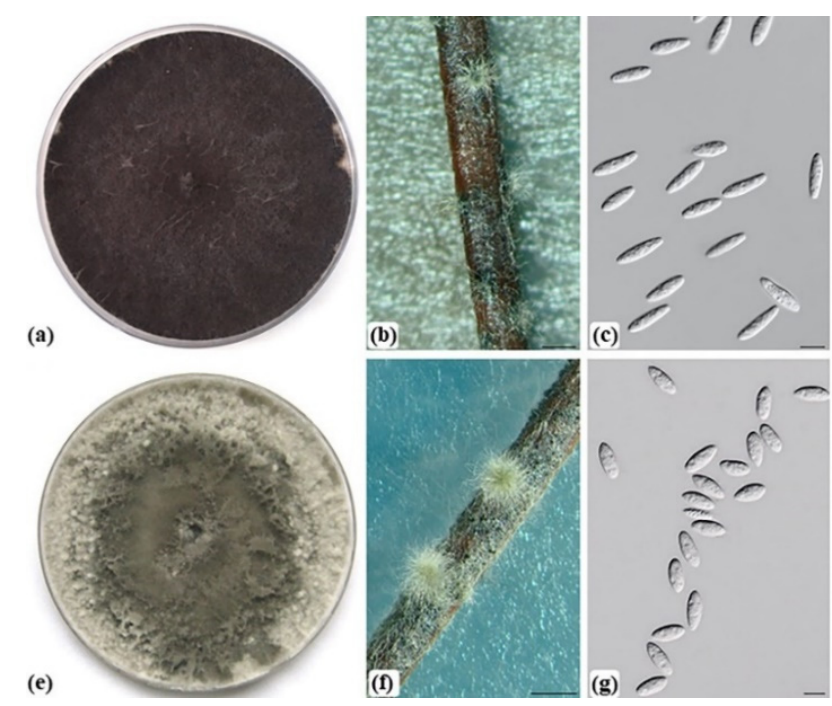

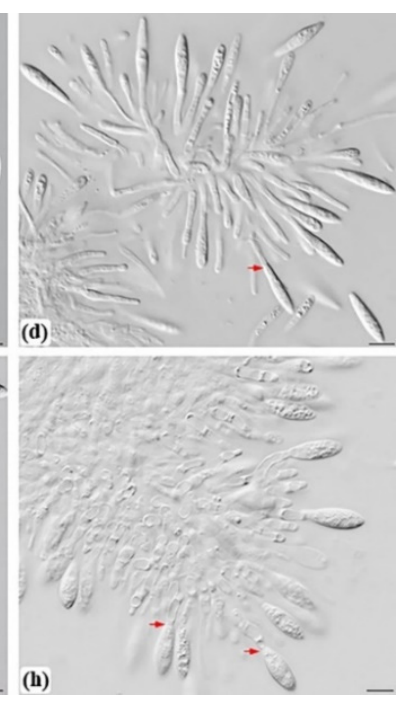

Figure 2. Morphological characteristics of Botryosphaeria dothidea (ILFE 2) and Neofusicoccum yunnanense (ILFE 4) isolated and identified in this study. (a,e). 14-day old culture of B. dothidea (a) and N. yunnanense (e) growing on MEA at $25^{\circ} \mathrm{C}$. $(\mathbf{b}, \mathbf{f})$. Superficial globose pycnidia of B. dothidea (b) and $N$. yunnanense (f) covered with mycelium. (c). Hyaline, aseptate fusiform conidia of B. dothidea. (d,h). Conidia of B. dothidea (d) and N. yunnanense (h) developing on conidiogenous cells. Annellations are marked with arrows (d,h). (g). Hyaline, aseptate, fusiform to ellipsoidal conidia of N. yunnanense. Scale bars: $1 \mathrm{~mm}(\mathbf{b}, \mathbf{f}), 10 \mu \mathrm{m}(\mathbf{c}, \mathbf{d}, \mathbf{g}, \mathbf{h})$.

\subsection{Phylogenetic Analyses}

The best fit models of nucleotide substitution used in the analyses of the individual genes were as follows: GTR + G (ITS; G = 0.499), GTR + G + I (tef 1- $\alpha ; G=0.499, \mathrm{I}=0.105)$, and HKY $85+\mathrm{G}$ (TUB2; $\mathrm{G}=0.279$ ). $\mathrm{ML}$ and $\mathrm{BI}$ analyses of the individual genes resulted in trees with congruent topologies (Figure S1). The concatenated dataset with the tree loci (ITS + tef 1- $\alpha+$ TUB2) of 50 sequences including P. stromaticum as an outgroup (12 sequences generated in this study and 38 retrieved from GenBank) resulted in 1292 characters of which 453 characters were parsimony informative and 839 characters were parsimony uninformative (Table 1). For ML and BI analyses, the model GTR + G + I ( $G=0.791$, $\mathrm{I}=0.401)$ was selected as the best fit model of nucleotide substitution. For MP analyses, PHT test indicated that the loci are suitable to be combined $(p=0.03)$. Tree topologies resulting from ML, BI and MP analyses (37 equally most parsimonious trees, $\mathrm{CI}=0.8$, $\mathrm{RI}=0.9, \mathrm{TL}=643$ ) of the concatenated dataset were similar, with minor differences in the positions of subclades and the ML tree is shown in Figure 3. Phylogenetic analyses of the combined ITS/tef 1- $\alpha$ /TUB2 dataset revealed two major and strongly supported clades, each representing a separate genus, including Botryosphaeria and Neofusicoccum (Figure 3).

In the ITS, tef $1-\alpha$ and combined ITS/tef 1- $\alpha$ /TUB2 trees isolates ILFE 2 and ILFE 3 clustered within the clade corresponding to B. dothidea (Figure S1, Figure 3). These isolates had only one single nucleotide polymorphism (SNP) that differentiated them from the type strain of B. dothidea CMW 8000 (Table 2). 


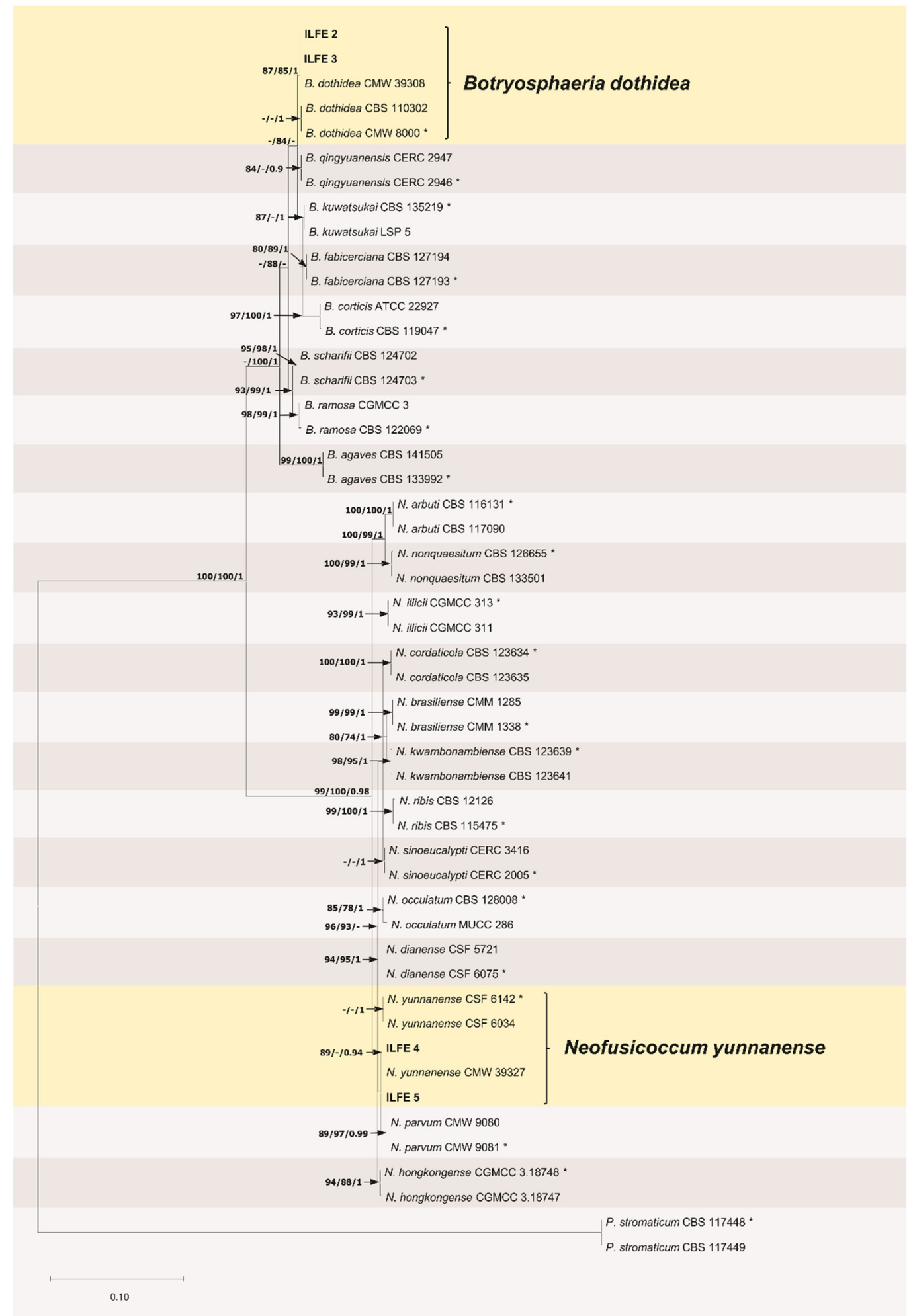

Figure 3. Phylogenetic tree generated from a maximum likelyhood analyses (ML) based on a concatenated alignment of ITS, tef 1- $\alpha$ and TUB2 sequences data showing the position of Botryosphaeria dothidea and Neofusicoccum yunannense in relation to their closely related species. ML and MP bootstrap support values greater than $70 \%$ and Bayesian posterior probability values (PP) greater than 0.90 are indicated at the tree nodes (ML/MP/PP). Clades corresponding to N. yunnanense and B. dothidea are highlighted. The type strains are marked with an asterisk and isolates obtained in this study are shown in bold. Pseudofisicoccum stromaticum (CBS 117448 and CMW 117449) was included as an outgroup. Scale bar indicates expected number of substitutions per site. 
Table 2. Polymorphisms in the nucleotide sequences of ITS, tef 1- $\alpha$ and TUB2 loci between isolates ILFE 4, ILFE 5, CMW 39327, N. yunnanense, and N. parvum and between isolates ILFE 2, ILFE 3, and B. dothidea. The ex-type strains are marked with an asterisk and shared polymorphisms are highlighted in grey.

\begin{tabular}{cccccccc}
\hline \multirow{2}{*}{ Isolates } & \multicolumn{1}{c}{ Locus } & & \\
\cline { 2 - 8 } & ITS & & & tef 1- $\boldsymbol{c}$ & \multicolumn{2}{c}{ TUB2 } \\
\hline & 48 & 147 & 290 & 294 & 322 & 386 & 404 \\
N. parvum CMW 9081 * & T & C & A & A & T & T & T \\
N. parvum CMW 9080 & T & C & A & A & T & T & T \\
N. yunnanense CSF 6142 * & A & T & G & C & C & C & C \\
N. yunnanense CSF 6034 & A & T & G & C & C & C & C \\
CMW 39327 & A & C & G & C & C & C & C \\
ILFE 4 & A & C & G & C & C & C & C \\
ILFE 5 & A & C & G & C & C & C & C \\
B. dothidea 8000* & & & & & T & & \\
B. dothidea CBS 110302 & & & & & T & & \\
B. dothidea CMW 39308 & & & & & C & & \\
ILFE 2 & & & & & C & & \\
ILFE 3 & & & & & C & & \\
\hline
\end{tabular}

In both analyses of individual genes and combined ITS/tef 1- $\alpha /$ TUB2 tree isolates ILFE 4 and ILFE 5 clustered within the clade corresponding to N. yunnanense. There was only one SNP that differentiated these isolates from the type strain of N. yunnanense CSF 6142 and six SNPs differentiated them from the type strain CMW 9081 of the phylogenetically close species $N$. parvum (Table 2). In the combined ITS/tef 1- $\alpha /$ TUB2 tree the clade corresponding to N. parvum was strongly supported in all three analyses $(89 / 97 \% \mathrm{ML}$, MP bootstrap support; Posterior probability: 1) and the clade corresponding to N. yunnanense was strongly supported in ML, weakly supported in MP analyses, and moderately supported in BI analyses (89/66\% ML, MP bootstrap support; Posterior probability: 0.94). Based on phylogenetic analyses, isolates from this study were identified as B. dothidea and N. yunnanense.

\subsection{Pathogenicity Test}

Three weeks after inoculation, $30 \%$ of the plants inoculated with $N$. yunnanense showed disease symptoms such as wilting and die-back. Moreover, sunken, resinous cankers $(<2 \mathrm{~cm})$ were evident on the stems after the parafilm was removed. The disease progressed; the cankers enlarged, leading further to wilting and consequent death of the plants. Needles were dry and necrotic and fruit bodies (pycnidia) containing fusiform to ellipsoidal spores typical for Neofusicoccum spp. developed within cankers. The remaining plants developed resinous cankers with cracked bark in some of the plants measuring $2.1-2.6 \mathrm{~cm}$ (av. $2.3 \mathrm{~cm}$ ). In addition, $40-60 \%$ of foliage of these plants was wilted, dry and necrotic. Plants inoculated with $B$. dothidea exhibited only resinous cankers measuring $1.3-1.8 \mathrm{~cm}$ (av. $1.4 \mathrm{~cm}$ ). There was a statistically significant difference between the canker lengths produced by $N$. yunnanense and B. dothidea ( $\mathrm{U}=0.00, p<0.001$ two-tailed). Control seedlings showed no disease symptoms (Figure 4). Both fungi were re-isolated from the canker margins on inoculated plants, but not from the control plants, completing Koch's postulates. 

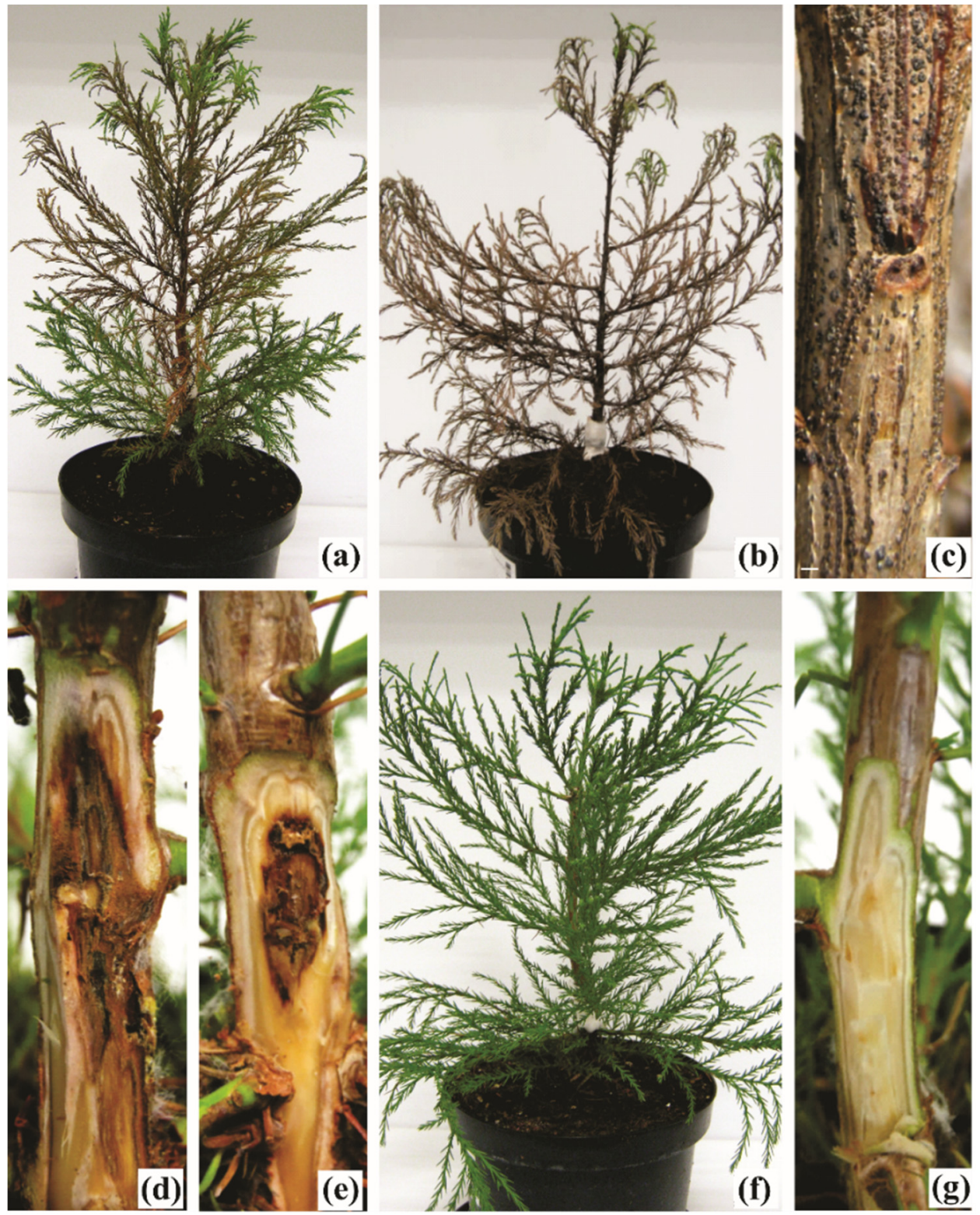

Figure 4. Disease symptoms and signs associated with Neofusicoccum yunnanense and Botryosphaeria dothidea on inoculated Sequoiadendron giganteum seedlings. $(\mathbf{a}, \mathbf{b})$. Browning and drying of the needles from inoculation point upwards after inoculation with N. yunnanense ILFE 5 (a) and ILFE 4 (b). (c). Pycnidia of N. yunnanense formed in the cankered tissue after inoculation with N. yunnanense ILFE 4. (d). Girdling, resin-soaked canker formed after inoculation with N. yunnanense ILFE 5. (e). Resinous canker formed after inoculation with B. dothidea ILFE 2. (f,g). Control seedling inoculated with sterile MEA plug showing no disease symptoms. Scale bar: $5 \mathrm{~mm}$ (c).

\section{Discussion}

The current study presents the first record of B. dothidea and N. yunnanense on $S$. gigateum in Croatia. The known geographic and host range of $N$. yunnanense was expanded and the host association of $B$. dothidea with $S$. giganteum was confirmed. The fungi were identified using morphology, phylogenetic analyses of the ITS rDNA and two housekeeping genes (tef 1- $\alpha$ and TUB2). The pathogenicity test showed that B. dothidea and N. yunnanense are the causal agents of the canker and die-back disease of $S$. giganteum in Croatia.

The present study is also the first report of any disease of $S$. giganteum in Croatia. Even though these trees have been planted as ornamentals for more than 150 years in this 
country (the first S. giganteum tree was planted in 1862 in Zagreb) [29], prior to this study no research has been conducted on diseases of $S$. giganteum in Croatia. Moreover, little research has been conducted on diseases of S. giganteum in Southeastern Europe and the only studies are related to the die-back caused by Botryosphaeriaceae fungi, including $B$. dothidea, N. parvum and D. omnivora in Serbia and Greece [11,13,14]. Die-back symptoms have also recently been observed in Bulgaria, and Botryosphaeriaceae have been suspected to be the cause of the disease [12].

The isolation and pathogenicity of $B$. dothidea towards S. giganteum in Croatia is not unexpected given that it is a plurivorous and widespread species, and a well-known pathogen of forest and ornamental trees [14,17]. B. dothidea produced cankers on stems when inoculated, although it was less aggressive compared to N. yunnanense and did not cause symptoms of wilting and die-back. In contrast, in a study of Zlatković et al. [14] B. dothidea was able to produce girdling cankers and cause death of $S$. giganteum seedlings 13 weeks after inoculation. However, the test was carried out under field conditions, the seedlings were younger (2-year-old compared to 3-year-old seedlings used in this study) and the $B$. dothidea isolates used for inoculation originated from Chamaecyparis lawsoniana (A. Murray) Parl. Moreover, Worral et al. [30] isolated B. dothidea from S. giganteum in California. The later study showed that $B$. dothidea can produce symptoms of die-back and cause death of 2-year-old $S$. giganteum seedlings five weeks after inoculation in the greenhouse. However, the isolates were identified using morphological data alone and hence their identity remained unclear. In addition, Haenzi et al. [16] reported B. dothidea from symptomatic $S$. giganteum trees in Switzerland, but the pathogenicity of the fungus towards S. giganteum was not tested. Furtermore, Morelet et al. [7], Kehr et al. [8], Cech et al. [9], Vajna et al. [10] and Georgieva [12] isolated B. dothidea from S. giganteum showing die-back symptoms in France, Germany, Austria, Hungary, and Bulgaria, respectively. However, in these studies the species was identified using morphology only and the pathogenicity test was not conducted. Although $B$. dothidea has a worldwide distribution, in Croatia the species has been previously isolated only from Vitis vinifera $\mathrm{L}$, but it remained unknown if $B$. dothidea is a pathogen of grapevine in this country [31].

Neofusicoccum yunnanense was isolated from S. giganteum in this study. Neofusicoccum species have previously been reported associated with $S$. giganteum trees and are known to have a broad host range $[14,17,19]$. For example, Neofusicoccum mediterraneum Crous, M.J. Wingf. and A.J.L. Phillips and N. nonquaesitum have been isolated from S. giganteum in California (USA) [6,32]; Neofusicoccum australe (Slippers, Crous and M.J. Wingf.) Crous, Slippers and A.J.L. Phillips has been found associated with S. giganteum in Australia [33]; N. parvum has been isolated from S. giganteum in Greece, Switzerland, and Serbia, respectively $[11,14,16]$. N. yunnanese has recently been described from China, where it was isolated from Eucalyptus globulus Labill., E. urophylla $\times$ E. grandis hybrid, and Eucalyptus sp. [34]. In this study however, N. yunnanense was isolated from $S$. giganteum and it seems that this species is not host-specific, as with most of the members of the Botryosphaeriaceae [14,19]. Conidia of isolates of $N$. yunnanense from this study $(17.8 \times 6.7 \mu \mathrm{m}, 1 / \mathrm{w} 2.7)$ were on average bigger and less narrow compared to those of the type strain of $N$. yunnanense $(15.6 \times 4.4 \mu \mathrm{m}, 1 / \mathrm{w} 3.5)$ [34]. However, this is consistent with the view that the use of morphological data for species identification in the Botryosphaeriaceae is unreliable. This was highlighted in previous studies $[13,17,21]$, including in that by Slippers et al. [20] who also provided the argument that Botryosphaeriaceae morphological characters have evolved more than once.

Interestingly, in the phylogenetic analyses, isolates of $N$. yunnanense from China (including the type strain) clustered with isolates from this study and with an isolate CMW 39327 isolated from S. giganteum in Serbia. Previous study of Zlatković et al. [14] has identified the isolate CMW 39327 as $N$. parvum, but this was before the description of $N$. yunnanense. Recently, Zhang et al. [21] reassessed the identity of the 499 isolates in the culture collection (CBS) of the Wersterdijk Institute in the Netherlands, including species of the Botryosphaeriaceae. However, the work did not consider all strains of N. parvum 
isolated from S. giganteum in the previous studies and did not include N. yunnanense. Further studies are necessary to clarify the identity of the global collection of isolates of the N. parvum species complex from S. giganteum. Moreover, given the small number of isolates sequenced in this study along with restricted sampling area, we cannot exclude the possibility of presence of $N$. parvum along with $N$. yunnanense on S. giganteum in Croatia and further investigations are required to better understand the diversity and impact of Botryosphaeriaceae on this host.

In this study, N. yunnanense was pathogenic towards S. giganteum and it was more aggressive compared to $B$. dothidea. Apart from producing cankers on the inoculated seedlings, N. yunnanense was able to produce symptoms of wilting and die-back such as those seen on mature trees under natural conditions and kill the seedlings seven weeks after inoculation. This is consistent with the results of the previous studies where Neofusicoccum species were among the most aggressive members of the Botryosphaeriaceae. For example, pathogenicity tests on Sequoia sempervirens (D. Don) Endl., the closest relative of S. giganteum have shown that Neofusicoccum species were more aggressive compared to $B$. dothidea and produced the largest lesions [35]. Moreover, in a study of Lazzizera et al. [36] Neofusicoccum vitifusiforme (Van Niekerk and Crous) Crous, Slippers and A.J.L. Phillips was more aggressive compared to $B$. dothidea when inoculated onto Olea europaea L. Furthermore, a study of Rooney-Latham et al. [6] had shown that N. nonquaesitum can produce black, sunken cankers and cause wilting of $S$. giganteum seedlings 14 days after inoculation in the greenhouse. In addition, in a study by Tsopelas et al. [11] N. parvum caused cankers and die-back of branches of mature S. giganteum trees eight weeks after inoculation. Additionally, pathogenicity results of Zlatković et al. [14] and Haenzi et al. [16] suggested that $N$. paroum is an important pathogen of $S$. giganteum, able to produce cankers and die-back when inoculated onto seedlings of S. giganteum.

The die-back of $S$. giganteum observed in this study could be related to various forms of stress to which trees growing in unique ecological conditions of urban sites are exposed (i.e., soil compaction, air pollution, "Heat island effect"). During the last decade, Croatia has experienced several warmest and driest years since measurements begun, accompanied by several "Heat waves" [37]. Similarly, Morelet et al. [7], Kehr et al. [8], Cech et al. [9] and Zlatković et al. [15] speculated that Botryosphaeriaceae related die-back of S. giganteum could be linked to an increase in extreme weather events, and other stresses that trees planted in urban areas experience. In addition, S. giganteum is a tree species with high water demand that naturally occurs in an area with relatively abundant water supply which is much higher than that in Zagreb where symptoms of die-back have been observed [2,37]. Additionally, in its native range, S. giganteum populations are confined to a mid-elevation range (1400-2150 m) [2], whereas, in Zagreb, these trees had been planted on low elevation sites (115-254 m) [29]. These conditions could have suppressed S. giganteum health and triggered the Botryosphaeriaceae related disease. This is consistent with the opportunistic nature of these fungi that are typically associated with plant stress [19].

In this study, N. yunnanense and B. dothidea have been isolated from S. giganteum trees planted in urban green spaces, i.e., a city park, a private garden, a botanical garden, and an arboretum. Botanical gardens and arboreta with diverse international plant collections represent dense assemblages of various tree species, including conifers and broadleaves, native and introduced trees, and are standing sentinels for the potentially invasive pathogens [38]. Botryosphaeriaceae are known to infect a wide range of hosts and can move between tree species $[14,19]$ and it might be possible that other nearby trees have also been infected. Moreover, in this study, die-back symptoms have been observed on mature trees, and it is not known if the disease is also present in Croatian nurseries. Similarly, die-back of mature S. giganteum trees has been found in Switzerland, USA, and Greece $[6,11,16]$, whereas Kehr et al. [8] and Georgieva et al. [12] reported the presence of disease symptoms on trees of all ages in Germany and Bulgaria, respectively. In addition, crown die-back has been associated with an advance stage of the disease development in this study but standing dead S. giganteum trees have not been found. In contrast, Botryosphaeriaceae related 
S. giganteum tree mortality has been reported from Switzerland and Bulgaria [12,16], and it has also recently been observed in Serbia [39]. Therefore, a detailed tree health survey of the rest of the tree species planted in Zagreb's green places, as well as S. giganteum seedlings and trees in nurseries and landscapes across Croatia is urgently needed to examine the possibility or the magnitude of the spread of the disease and develop measures for disease prevention and control to minimize economic and environmental impacts.

Botryosphaeriaceae invade vascular tissues of trees and thus the safe and effective control of diseases caused by these fungi represents a challenge [19,40]. Moreover, management options for trees in urban environments are limited due to the potentially harmful impacts of residues of chemical fungicides on human health and the environment [41]. Horticultural practices such as mulching, watering, pruning of the infected branches, pruning during the dormant season or at least during dry periods to prevent infection by water splashed spores, can be used to reduce stress to trees and prevent die-back [36]. Additionally, various biological control strategies for management of the Botryosphaeriaceae diseases are being developed and the preliminary results are promising [42-44].

\section{Conclusions}

To the best of our knowledge, this work represents the first report of $B$. dothidea and $N$. yunnanense as pathogens of S. giganteum in Croatia. It is also the first report on the identity and pathogenicity of any fungal species associated with S. giganteum in this country. The host range of $N$. yunnanense has been expanded and the host association of $B$. dothidea with $S$. giganteum has been confirmed. Considering high social, and landscape value that S. giganteum trees have in Croatian urban areas, and the fact that most trees have been protected by the Law as horticultural monuments [29], the magnitude of this problem should not be neglected, and special attention should be paid to those trees. An integrated disease management approach, focusing on horticultural practices and biological control is needed to mitigate or reduce the impact of the disease.

Supplementary Materials: The following are available online at https:/ /www.mdpi.com/article/10 .3390/f12060695/s1, Table S1: Sequoiadendron giganteum trees sampled in this study, Table S2: PCR conditions used in this study, Figure S1: Phylogenetic trees generated from Bayesian interference analyses based on a single gene alignment of ITS, tef 1- $\alpha$ and TUB2 sequences data showing the relationships of Botryosphaeria dothidea and Neofusicoccum yunannense with closely related species. ML bootstrap support values greater than $70 \%$ and Bayesian posterior probability values (PP) greater than 0.90 are indicated at the tree nodes (ML/PP). Clades corresponding to N. yunnanense and B. dothidea are highlighted. The type strains are marked with an asterisk and isolates sequenced in this study are marked with degree sign. Pseudofisicoccum stromaticum (CBS 117448 and CMW 117449) was included as an outgroup. Scale bar indicates expected nuber of substitutions per site.

Author Contributions: Conceptualization, M.Z. and M.K.; methodology, M.Z.; investigation, M.K.; resources, S.O., M.K. and D.D.; data curation, M.Z. and M.K.; writing-original draft preparation, M.K. and M.Z.; writing-review and editing, M.K., M.Z., S.O. and D.D.; visualization, M.K. and M.Z.; funding acquisition, S.O., M.K. and D.D. All authors have read and agreed to the published version of the manuscript.

Funding: This research was funded by the Ministry of education, science and technological development of the Republic of Serbia, project no. 451-03-9/2021-14/200197; Diagnostic and Prognostic Service (IPP) of the Ministry of Agriculture of the Republic of Croatia and the University of Zagreb, Faculty of Forestry and Wood Technology. The first author was partially funded by the European Cooperation in Science and Technology (COST) action "A global network of nurseries as early warning system against alien tree pests" (Global Warning FP1401).

Data Availability Statement: not applicable.

Acknowledgments: The authors wish to acknowledge Bernard Slippers (Forestry and Agricultural Biotechnology Institute-FABI, University of Pretoria) for valuable suggestions regarding species boundaries in the Botryosphaeriaceae; ShuaiFei Chen (China Eucalypt Research Centre- CERC, Chinese Academy of Forestry) and Guoqing $\operatorname{Li}(\mathrm{CERC})$ for providing sequences of $N$. yunnanense when they 
were still not available in the GenBank; Milan Pernek (Croatian Forest Research Institute) and Milica Mihajlović (Institute of Pesticides and Environmental Protection, Belgrade, Serbia) for the logistical support; Sreten Vasić (Institute of Lowland Forestry and Environment-ILFE, University of Novi Sad) for the technical assistance. Vanja Stamenković (Botanical Garden of the Faculty of Science, University of Zagreb) is thanked for the permission and help with sampling in the botanical garden.

Conflicts of Interest: The authors declare no conflict of interest. The funders had no role in the design of the study; in the collection, analyses, or interpretation of data; in the writing of the manuscript, or in the decision to publish the results.

\section{References}

1. Harvey, H.T.; Shellhammer, H.S.; Stecker, R.E. Giant Sequoia Ecology: Fire and Reproduction; Scientific Monograph Series No. 12, U.S. Department of the Interior, National Park Service: Washington, DC, USA, 1980; p. 221.

2. $\quad$ Paz-Kagan, T.; Vaughn, N.R.; Martin, R.E.; Brodrick, P.G.; Stephenson, N.L.; Das, A.J.; Nydick, K.R.; Asner, G.P. Landscape-scale variation in canopy water content of giant sequoias during drought. For. Ecol. Manag. 2018, 419, 291-304. [CrossRef]

3. Dodd, R.S.; DeSilva, R. Long-term demographic decline and late glacial divergence in a Californian paleoendemic: Sequoiadendron giganteum (giant sequoia). Ecol. Evol. 2016, 6, 3342-3355. [CrossRef]

4. IUCN Red List of Threatened Species (Ver. 3.1). Available online: http:/ / www.iucnredlist.org (accessed on 23 March 2021).

5. Nydick, K.R.; Stephenson, N.L.; Ambrose, A.R.; Asner, G.P.; Baxter, W.B.; Das, A.J.; Dawson, T.; Martin, R.E.; Paz-Kagan, T. Leaf to landscape responses of giant sequoia to hotter drought: An introduction and synthesis for the special section. For. Ecol. Manag. 2018, 419-420, 249-256. [CrossRef]

6. Rooney-Latham, S.; Tidwell, T.E.; Blomquist, C.L.; Peek, K.S. First report of Neofusicoccum nonquaesitum causing branch cankers on giant sequoia (Sequoiadendron giganteum) in North America. Plant Dis. 2012, 96, 905. [CrossRef] [PubMed]

7. Morelet, M.; Andréoli, C.; Chandelier, P.; Ménard, J.-E. Botryosphaeria dothidea, agent de chancre sur Sequoiadendron giganteum. Rev. For. Franc. 1993, 45, 37-42. (In French) [CrossRef]

8. Kehr, R. Branch dieback of giant sequoia (Sequoiadendron giganteum) in Germany caused by Botryosphaeria dothidea. Nachr. Des. Dtsch. Pflanzenschutzd. 2004, 56, 37-43. (In German)

9. Cech, T.L.; Christian, T. Increasing prevalence of Botryosphaeria-canker (Botryosphaeria dothidea) of giant sequoia in Eastern Austria. Forstsch. Aktuell 2013, 57, 37-40, (In German with an English abstract).

10. Vajna, L.; Schwarczinger, I. Fungi causing branch dieback of giant sequoia (Sequoiadendron giganteum (Lindl.) Buchholcz) in Hungary. Növényvédelem 1998, 34, 133-136, (In Hungarian with an English abstract).

11. Tsopelas, P.; Slippers, B.; Wingfield, M.J.; Zagkou, Z.G. Infection of Sequoiadendron giganteum in Greece by the fungus Neofusicoccum parvum. In Proceedings of the 14th National Congress of Hellenic Phytopathological Society, Argolida, Greece, 7-10 October 2008.

12. Georgieva, M. First record of the pathogen Botryosphaeria dothidea associated with Sequoiadendron giganteum in Bulgaria. Silva Balcanica 2016, 17, 57-62.

13. Zlatković, M.; Keča, N.; Wingfield, M.J.; Jami, F.; Slippers, B. Botryosphaeriaceae associated with the die-back of ornamental trees in the Western Balkans. Antonie Van Leeuwenhoek 2016, 109, 543-564. [CrossRef]

14. Zlatković, M.; Wingfield, M.J.; Jami, F.; Slippers, B. Host specificity of co-infecting Botryosphaeriaceae on ornamental and forest trees in the Western Balkans. For. Path. 2018, 48, e12410. [CrossRef]

15. Zlatković, M. Botryosphaeriaceae species associated with canker and die-back disease of conifers in urban environments in Serbia. Topola/Poplar 2017, 199, 55-75, (In Serbian with an English summary).

16. Haenzi, M.; Cochard, B.; Chablais, R.; Crovadore, J.; Lefort, F. Neofusicoccum parvum, a new agent of sequoia canker and dieback identified in Geneva, Switzerland. Forests 2021, 12, 434. [CrossRef]

17. Pavlic-Zupanc, D.; Maleme, H.M.; Piškur, B.; Wingfield, B.D.; Wingfield, M.J.; Slippers, B. Diversity, phylogeny and pathogenicity of Botryosphaeriaceae on non-native Eucalyptus grown in an urban environment: A case study. Urban For. Urban Green. 2017, 26, 139-148. [CrossRef]

18. Moricca, S.; Uccello, A.; Ginetti, B.; Ragazzi, A. First report of Neofusicoccum parvum associated with bark canker and dieback of Acer pseudoplatanus and Quercus robur in Italy. Plant Dis. 2012, 96, 1699. [CrossRef] [PubMed]

19. Slippers, B.; Wingfield, M.J. Botryosphaeriaceae as endophytes and latent pathogens of woody plants: Diversity, ecology and impact. Fungal Biol. Rev. 2007, 21, 90-106. [CrossRef]

20. Slippers, B.; Boissin, E.; Phillips, A.J.L.; Groenewald, J.Z.; Lombard, L.; Wingfield, M.J.; Postma, A.; Burgess, T.; Crous, P.W. Phylogenetic lineages in the Botryosphaeriales: A systematic and evolutionary framework. Stud. Mycol. 2013, 76, 31-49. [CrossRef]

21. Zhang, W.; Groenewald, J.Z.; Lombard, L.; Schumacher, R.K.; Phillips, A.J.L.; Crous, P.W. Evaluating species in Botryosphaeriales. Persoonia 2021, 46, 63-115. [CrossRef]

22. Gardes, M.; Bruns, T.D. ITS primers with enhanced specificity for basidiomycetes-application to the identification of mycorrhizae and rusts. Mol. Ecol. 1993, 2, 113-118. [CrossRef] 
23. White, T.J.; Bruns, T.; Lee, S.; Taylor, J.; Innis, M.A.; Gelfand, D.H.; Sninsky, J.J.; White, T.J. Amplification and direct sequencing of fungal ribosomal RNA genes for phylogenetics. In PCR Protocols: A Guide to Methods and Applications Innis MA; Gelfand, D.H., Sninsky, J.J., White, T.J., Eds.; Academic Press: New York, NY, USA, 1990; pp. 315-322.

24. Darren, K.J.; Mattick, J.S. Touchdown PCR for increased specificity and sensitivity in PCR amplification. Nature Protocols 2008, 3, 1452. [CrossRef]

25. Zlatković, M.; Tenorio-Baigorria, I.; Lakatos, T.; Tóth, T.; Koltay, A.; Pap, P.; Marković, M.; Orlović, S. Bacterial canker disease on Populus $\times$ euramericana caused by Lonsdalea populi in Serbia. Forests 2020, 11, 1080. [CrossRef]

26. Taylor, D.W.; Jacobson, D.J.; Kroken, S.; Kasuga, T.; Geiser, D.M.; Hibbett, D.S.; Fisher, M.C. Phylogenetic species recognition and species concepts in fungi. Fungal Genet. Biol. 2000, 31, 21-32. [CrossRef]

27. Zlatković, M.; Keča, N.; Wingfield, M.W.; Jami, F.; Slippers, B. New and unexpected host associations for Diplodia sapinea in the Western Balkans. For. Path. 2017, 47, e12328. [CrossRef]

28. Lefort, V.; Longueville, J.-E.; Gascuel, O. SMS: Smart Model Selection in PhyML. Mol. Biol. Evol. 2017, 34, 2422-2424. [CrossRef]

29. Jurković, M.; Jurković-Bevilacqua, B. Golemi mamutovac- Sequoiadendron giganteum (Lindl.) Buchh. u zagrebačkim parkovima. Sumar. List 1996, 1-2, 47-53. (In Croatian)

30. Worral, J.J.; Correll, J.C.; McCain, A.H. Pathogenicity and teleomorph-anamorph connection of Botryosphaeria dothidea on Sequoiadendron giganteum and Sequoia sempervirens. Plant Dis. 1986, 70, 757-759. [CrossRef]

31. Kaliterna, J.; Miličević, T. In Proceedings of the Incidence and Distribution of Fungi from Diaporthaceae and Botryosphaeriaceae on Grapevine in Croatia. In Proceedings of the 11th Conference of the European Foundation for Plant Pathology: Healthy Plants-Healthy People, Krakov, Poland, 8-13 September 2014.

32. Inderbitzin, P.; Bostock, R.M.; Trouillas, F.P.; Michailides, T.J. A six locus phylogeny reveals high species diversity in Botryosphaeriaceae from California almond. Mycologia 2010, 102, 1350-1368. [CrossRef] [PubMed]

33. Slippers, B.; Fourie, G.; Crous, P.W.; Coutinho, T.A.; Wingfield, B.D.; Wingfield, M.J. Multiple gene sequences delimit Botryosphaeria australis sp. nov. from B. lutea. Mycologia 2004, 96, 1030-1041. [CrossRef]

34. Guoqing, L.; Slippers, B.; Wingfield, M.J.; Shuaifei. C. Variation in Botryosphaeriaceae from Eucalyptus plantations in YunNan Province in southwestern China across a climatic gradient. IMA Fungus 2020, 11, 1-49. [CrossRef]

35. Aćimović, S.; Rooney-Latham, S.; Albu, S.; Grosman, D.M.; Doccola, J.J. Characterization and pathogenicity of Botryosphaeriaceae fungi associated with declining urban stands of coast redwood in California. Plant Dis. 2018, 102, 1950-1957. [CrossRef] [PubMed]

36. Lazzizera, C.; Frisullo, S.; Alves, A.; Phillips, A.J.L. Morphology, phylogeny and pathogenicity of Botryosphaeria and Neofusicoccum species associated with drupe rot of olives in southern Italy. Plant Path. 2008, 57, 948-956. [CrossRef]

37. State Hydrometeorological Institute. Available online: www.meto.hr (accessed on 13 April 2021).

38. Eschen, R.; O'Hanlon, R.; Santini, A.; Vannini, A.; Roques, A.; Kirichenko, N.; Kenis, M. Safeguarding global plant health: The rise of sentinels. J. Pest Sci. 2019, 92, 29-36. [CrossRef]

39. Orlović, S.; Zlatković, M.; (Institute of Lowland Forestry and Environment (ILFE), University of Novi Sad, Novi Sad, Serbia). Personal communication, 2021.

40. Aćimović, S.G.; Martin, D.K.H.; Turcotte, R.M.; Meredith, C.L.; Munck, I.A. Choosing an adequate pesticide delivery system for managing pathogens with difficult biologies: Case studies on Diplodia corticola, Venturia inaequalis and Erwinia amylovora. Plant Dis. Curr. Threat. Manag. Trends 2019. [CrossRef]

41. Karen, J.; Paine, T.D. Consumer preferences and willingness to pay for biological control in the urban landscape. Biol. Cont. 2004, 30, 312-322. [CrossRef]

42. Karličić, V.; Jovičić-Petrović, J.; Marojević, V.; Zlatković, M.; Orlović, S.; Raičević, V. Potential of Trichoderma spp. and Pinus sylvestris bark extracts as biocontrol agents against fungal pathogens residing in the Botryosphaeriales. Environ. Sci. Proc. 2020, 3, 99. [CrossRef]

43. Trotel-Aziz, P.; Abou-Mansour, E.; Courteaux, B.; Rabenoelina, F.; Clément, C.; Fontaine, F.; Aziz, A. Bacillus subtilis PTA-271 counteracts Botryosphaeria dieback in grapevine, triggering immune responses and detoxification of fungal phytotoxins. Front. Plant Sci. 2019, 10, 25. [CrossRef]

44. Zhai, L.; Xiang, J.; Zhang, M.; Fu, M.; Yang, Z.; Hong, N.; Wang, G. Characterization of a novel double-stranded RNA mycovirus conferring hypovirulence from the phytopathogenic fungus Botryosphaeria dothidea. Virology 2016, 493, 75-85. [CrossRef] 